\title{
THE EFFECTS OF PROCESSING ON STABILITY OF ALLOY 718
}

\author{
G. Shen*, J. Radavich**, X. Xie***, and B. Lindsley**** \\ ${ }^{*}$ Ladish Co., Inc. 5481 S. Packard Ave., Cudahy, WI 53110-8902, USA \\ ** Micro-Met Laboratories, Inc., 209 North Street, West Lafayette, IN 47906, USA \\ *** University of Science \& Technology Beijing, Beijing 100083, China \\ ****Special Metals Corporation, New Hartford, NY 13413, USA
}

\begin{abstract}
A program was undertaken to (1) investigate the degradation of mechanical properties of Alloy 718 processed in four different forging/heat treatment process combinations under the conditions of post forging thermal exposures and the combination of post forging cold work and thermal exposures and (2) to identify the initial microstructural changes which are associated with the mechanical property degradation in a temperature range of $593^{\circ} \mathrm{C}$ to $677^{\circ} \mathrm{C}$.
\end{abstract}

It was found that a significant impact degradation occurred after exposures at $593^{\circ} \mathrm{C}$ and $650^{\circ} \mathrm{C}$ but not as much as seen for exposures at $677^{\circ} \mathrm{C}$ for 1000 to 2000 hours. The Charpy impact energies after exposure were higher for samples which were given the standard Solution and Age (Super) while the hot tensile and notch rupture properties were better for samples given the Direct Age.

Embrittlement at temperatures of $650^{\circ} \mathrm{C}$ and higher is the result of large amounts of $\alpha \mathrm{Cr}$ phase and delta at the grain boundaries and overaging of the $\gamma$ " phase. The $\alpha \mathrm{Cr}$ precipitation is accelerated when the exposure temperature is above $650^{\circ} \mathrm{C}$. Residual strain from cold work was found to accelerate the $\alpha \mathrm{Cr}$ formation and promote Charpy property degradation. The $\alpha \mathrm{Cr}$ phase is found to precipitate at the $\gamma$-delta phase interface and is located mainly at the grain boundaries. The formation of $\alpha \mathrm{Cr}$ is attributed to the depletion of $\mathrm{Ni}$ and an enrichment of $\mathrm{Cr}$ as a result of $\mathrm{Cr}$ rejection during delta phase formation.

\section{Introduction}

Previous structural studies have shown that when Alloy 718 was exposed for long times at temperatures of $593^{\circ} \mathrm{C}$ to $760^{\circ} \mathrm{C}, \alpha \mathrm{Cr}$ formed in addition to delta phase $[1,2]$. Significant amounts of $\alpha \mathrm{Cr}$ have been found in retired engine disks. The degree of $\alpha \mathrm{Cr}$ formation has been found to be associated with the delta phase that formed during processing, heat treatment or during engine service. A significant drop in impact energy occurs when a large amount of $\alpha \mathrm{Cr}$ forms.

Recent studies [2,3] on Alloy 718 have shown that large amounts of residual strain produced by cold work will form $\alpha \mathrm{Cr}$ in short exposure times. Some highly strained Alloy 718 bolts, which have failed prematurely, have shown $\alpha \mathrm{Cr}$ to be present as a result of the initial heat treatment [3]. It has long been known that residual strain accelerates phase reactions. Varying amounts of residual strain in Alloy 718 disks produced by different forging processes may affect the rate of $\alpha \mathrm{Cr}$ formation and hence the structural stability. Understanding the formation of $\alpha \mathrm{Cr}$ and the associated property degradation is of great interest for aero and land based turbine applications. 
A research program was undertaken to study the stability of Alloy 718 under thermal exposure up to 2000 hours. A variety of forging and heat treatment conditions were used in processing the 718 disks used in this program. The objectives of the program were:

(1) To investigate the degradation of a variety of properties of the 718 disks processed in four different forging/heat treatment process combinations under the conditions of post forging thermal exposures and the combination of post forging cold work and thermal exposure;

(2) To investigate the microstructure deterioration associated with the mechanical property degradation.

\section{Experimental Procedures}

\section{Processes and Thermal Exposure Experiments}

Triple melt Alloy 718 was forged into a simple turbine disk configuration (Figure 1) using four different processes as shown in Table 1. The 718 had a composition (in weight \%) of $0.021 \mathrm{C}, 0.08 \mathrm{Mn}, 0.07 \mathrm{Si}$, $17.89 \mathrm{Cr}, 53.88 \mathrm{Ni}, 0.37 \mathrm{Co}, 2.99 \mathrm{Mo}, 0.94 \mathrm{Ti}, 0.49 \mathrm{Al}$, $0.0029 \mathrm{~B}, 0.0003 \mathrm{~S}, 0.01 \mathrm{P}, 0.05 \mathrm{Cu}, 0.01 \mathrm{Ta}, 5.36 \mathrm{Nb}$ and the balance $\mathrm{Fe}$. Two heat treatments were applied to these disks. One was direct age (DA) from forging operation. The other was post forging solution and age. The disks were then cut into sections for thermal exposures up to 2000 hours. The actual thermal exposure experiments are shown in Table 2. To detect the possible early structure changes, a 1000-hour exposure was used for all of the three thermal exposure temperatures and a 500-hour exposure was used for the exposure at $677^{\circ} \mathrm{C}$. To address the issue of the cold work/thermal exposure interaction, a set of samples was cold worked $9-16 \%$ and exposed at $650^{\circ} \mathrm{C}$ for 1000 hours. Two disks were processed for each of the four conditions listed in Table 1.

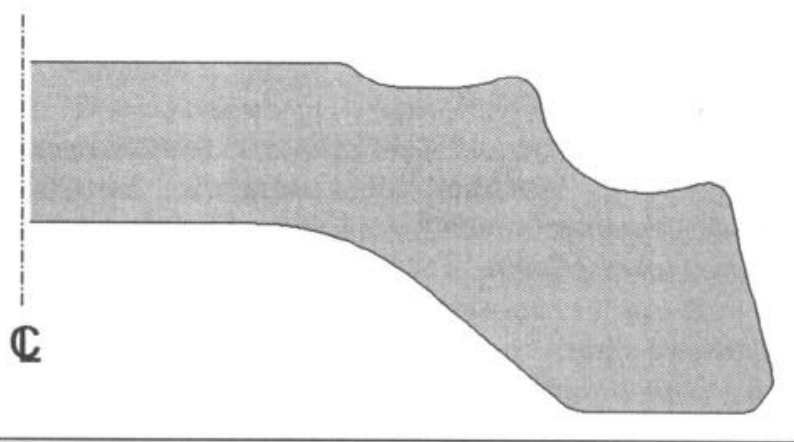

Figure 1. Half cross section of the disk (diameter $=280$ $\mathrm{mm}$ ) used in this research.

\section{$\underline{\text { Mechanical Tests }}$}

Hardness and Charpy tests were run on all conditions listed in Table 2. Hot tensile and notched rupture tests (notch factor $\mathrm{Kt}=3.6$ ) were run on all (except the cold work/thermal exposure) conditions listed in Table 2. Compact tension tests were run on selected samples.

\section{$\underline{\text { Structural Evaluations }}$}

Modified electrolytic techniques were developed and used to reveal the following: 1) $\alpha \mathrm{Cr}$ phase in relief, 2) preferential etching of the $\alpha \mathrm{Cr}$, or 3) both the $\alpha \mathrm{Cr}$ and delta phases as separate particles. Examples of such selective actions on $\alpha \mathrm{Cr}$ are shown in Figure 2. SEM studies were carried out on samples in all conditions listed in Table 2. X-ray diffraction of extracted residues was used to confirm the presence of the $\alpha \mathrm{Cr}$ phase.

Table 1. 718 Processed in Four Different Conditions

\begin{tabular}{|l|l|l|l|}
\hline Disk ID & Classification & \multicolumn{1}{|c|}{ Processes } & Grain Sizes \\
\hline 1,2 & DA-718 & Fine grain forging with Direct Age heat treatment & ASTM 11-12 \\
\hline 3,4 & Super-718 & Fine grain forging with solution + age heat treatment & ASTM 11-12 \\
\hline 5,6 & Super-II 718 & Ladish proprietary process (Special fine grain processing + DA) & ASTM 10-11 \\
\hline 7,8 & Standard-718 & Medium grain forging with solution + age heat treatment & ASTM 7-9 \\
\hline
\end{tabular}

Table 2. Thermal Exposure Experiments

\begin{tabular}{|c|c|c|c|c|}
\hline & 0 hour & 500 hours & 1000 hours & 2000 hours \\
\hline $593^{\circ} \mathrm{C}$ & \multirow[t]{3}{*}{ Disk $2,4,6,8$} & & Disk1,3,5,7 & Disk $1,3,5,7$ \\
\hline $650^{\circ} \mathrm{C}$ & & & $\begin{array}{l}\text { Disk1,3,5,7 } \\
\text { Disk } 1,3,5,7 \text { (cold work) }\end{array}$ & Disk1,3,5,7 \\
\hline $677^{\circ} \mathrm{C}$ & & Disk2,4,6,8 & Disk2, $4,6,8$ & Disk2,4,6,8 \\
\hline
\end{tabular}


However, the SEM metallographic technique was the primary tool to detect the $\alpha \mathrm{Cr}$ in the early stages of formation.

\section{Results}

\section{Mechanical Properties}

Hardness: There was no significant difference in hardness among the four groups of samples after exposures at $593^{\circ} \mathrm{C}, 650^{\circ} \mathrm{C}$, and $677^{\circ} \mathrm{C}$ for up to 2000 hours. The mean hardness of the four groups before the exposure was $45 \mathrm{HRc}$. After exposure at $593^{\circ} \mathrm{C}$ for 2000 hours the mean hardness of the four groups increased to 48HRc (age hardened). The mean hardness was $42 \mathrm{HRc}$ after exposure at $650^{\circ} \mathrm{C}$ for 2000 hours. The largest decrease in mean hardness appeared in samples exposed at $677^{\circ} \mathrm{C}$ for 2000 hours. The change was from $45 \mathrm{HRc}$ to $40 \mathrm{HRc}$.

Impact: The decrease in Charpy impact energy is dramatic. For an exposures up to 2000 hours at $593^{\circ} \mathrm{C}$, the Charpy impact energy dropped from 17.6J (DA-718) and 21.6J (Super-II 718) to 13.5J (DA-718) and 14.9J (Super-II 718), Figure 3(a), which represented a $23 \%$ and $31 \%$ reduction from the values obtained under unexposed condition for DA-718 and Super-II 718 respectively. After a 2000 hours at $677^{\circ} \mathrm{C}$, the lowest Charpy impact energies were 13.5J, $12.2 \mathrm{~J}, 10.8 \mathrm{~J}$, and 8.1J for Super-718, Standard-718, Super-II 718, and DA718 respectively. The Charpy value for DA-718 was the lowest both before and after the thermal exposure. The addition of cold work prior to exposure reduced the impact energy further. With a 9-16\% amount of cold work and a 1000 -hour thermal exposure at $650^{\circ} \mathrm{C}$, the Charpy impact energies of the samples are worse than samples without cold work exposed for 2000 hours at the same temperatures (Figure 3 (b)).

Hot Tensile: The hot tensile strength did not have any noticeable reduction after 2000 hour exposures at $593^{\circ} \mathrm{C}$ and $650^{\circ} \mathrm{C}$. However, a $19 \%$ decrease in hot tensile strength was found after exposure at $677^{\circ} \mathrm{C}$ for 2000 hours for all of the four group samples (Figure 4). The DA-718 and Super-II 718 had a better hot tensile strength both before and after the thermal exposures than the Super-718 and the Standard-718.

Notched Rupture: A decrease of more than $80 \%$ in notched rupture time was found after the exposure at $677^{\circ} \mathrm{C}$ for 2000 hours (Figure 5). The time to rupture for DA-718, Super-II 718, Standard-718, and Super-718 were $34,22,15$, and 8 hours respectively. DA-718 and Super-II 718 had longer notched rupture time than the
Super-718 and the Standard-718 both before and after the thermal exposures.

Structural Evaluations

$593^{\circ} \mathrm{C}$ : The etching out of the $\alpha \mathrm{Cr}$ technique was used to detect and follow the $\alpha \mathrm{Cr}$ formation with increasing exposure times and temperatures. $\alpha \mathrm{Cr}$ was most closely associated with the delta plates in the early stages of formation and then it was found also in the grain boundaries. After $1 \mathrm{Kh}$ of exposure, the $\alpha \mathrm{Cr}$ does not form in the standard 718 but does form in the DA-718 and the Super-II 718. More $\alpha \mathrm{Cr}$ is seen in the later two samples after $2 \mathrm{Kh}$ at $593^{\circ} \mathrm{C}$ while no $\alpha \mathrm{Cr}$ is found in the former sample.

$650^{\circ} \mathrm{C}$ : After $1 \mathrm{Kh}$ of exposure, more $\alpha \mathrm{Cr}$ was found in the DA-718 and Super-II 718 samples. $\alpha \mathrm{Cr}$ was found in the Standard-718 and the Super-718 after 2Kh but not as much as was found in the DA-718 and the Super-II 718. The $\gamma$ " phase also grew to a larger size comparing to that observed from samples exposed at $593^{\circ} \mathrm{C}$.

The cold worked samples all showed greater $\alpha \mathrm{Cr}$ formation compared to their counterparts that were not cold worked. Figure 6 shows the effect of cold work on $\alpha \mathrm{Cr}$ formation in the case of the Super 718 samples. The cold work also causes the growth of $\gamma^{\prime \prime} / \gamma^{\prime}$ phases.

677 ${ }^{\circ} \mathrm{C}:$ At this temperature $\alpha \mathrm{Cr}$ was detected after 500 hours in all samples, but greater amounts were found in the DA-718 and Super-II 718 samples. The $\alpha \mathrm{Cr}$ continued forming during the $1 \mathrm{Kh}$ and $2 \mathrm{Kh}$ exposures. While the $\alpha \mathrm{Cr}$ was forming, the $\gamma^{\prime \prime}$ phase was coarsening. The size of the $\gamma^{\prime \prime}$ after 500 hours at $677^{\circ} \mathrm{C}$ appears to be the same size as the $\gamma^{\prime \prime}$ found in $2 \mathrm{Kh}$ at $650^{\circ} \mathrm{C}$. Figure 7 shows the increased $\alpha \mathrm{Cr}$ amounts associated with the delta phase after $1 \mathrm{Kh}$ exposures at $593^{\circ} \mathrm{C}, 650^{\circ} \mathrm{C}$, and $677^{\circ} \mathrm{C}$. The coarsening of the $\gamma^{\prime \prime}$ is also clearly seen with increased temperatures of exposures.

\section{Conclusions}

Alloy 718 processed in four different ways showed property degradation after exposures at $593^{\circ} \mathrm{C}, 650^{\circ} \mathrm{C}$, and $677^{\circ} \mathrm{C}$ for up to 2000 hours. Among the three exposure temperatures, the $677^{\circ} \mathrm{C}$ gave the worst property degradation. The Charpy impact energies after exposure were higher for the Super-718 and Standard718 than the DA-718 and Super-II 718, while the DA718 and Super-II 718 had better hot tensile and notched rupture properties before and after exposure. Cold work was found to accelerate the Charpy property degradation as the cold worked samples showed much lower Charpy 
impact energies than those samples without cold work. These mechanical property changes appear to occur in shorter times than indicated by the published data of Radavich and Korth [1].

There is an interaction of the $\alpha \mathrm{Cr}$ and the delta phase as the $\alpha \mathrm{Cr}$ is found to precipitate at the $\gamma$-delta phase interface at temperatures as low as $593^{\circ} \mathrm{C}$. The initial $\alpha \mathrm{Cr}$ formation has not been previously shown in its early stages due to the fact that in metallographic preparation the top surface of the delta phase with its $\alpha \mathrm{Cr}$ layer is polished off and only the $\alpha \mathrm{Cr}$ on the sides and ends of the delta phase is retained.

The formation of $\alpha \mathrm{Cr}$ is thought to be due to the effects of residual strain and microsegregation of $\mathrm{Cr}$ as the delta phase forms. Similar $\alpha \mathrm{Cr}$ formation behavior in Ni base alloys having a large fraction of $\gamma^{\prime}$ was reported by Lemaire, Fornwalt, and Kear [4].

The $\alpha \mathrm{Cr}$ formation is accelerated when the temperatures of exposure go above $650^{\circ} \mathrm{C}$ as large amounts of $\mathrm{Cr}$ diffuse to the grain boundaries to form large discrete $\alpha \mathrm{Cr}$ while the $\gamma$ " coarsens in the matrix. Continued exposure at $650^{\circ} \mathrm{C}$ tends to form continuous film of $\alpha \mathrm{Cr}$ similar to
$\mathrm{M}_{23} \mathrm{C}_{6}$ carbides in $\mathrm{Ni}$ base alloys. Embrittlement of Alloy 718 is caused by large amount of $\alpha \mathrm{Cr}$ and the over aging of $\gamma^{\prime \prime} / \gamma^{\prime}$ phases.

\section{References}

[1] J. F. Radavich and G. E. Korth, "Effects of Very Long Time Aging in Alloy 718", TMS Annual Meeting, San Diego, CA 1992.

[2] B. Lindsley, X. Pierron, G. Maurer, and J. F. Radavich, " $\alpha-\mathrm{Cr}$ Formation in Alloy 718 During Long Term Exposure : The Effects of Chemistry and Deformation", TMS Annual Meeting, San Diego, CA 1999.

[3] J. F. Radavich, Unpublished Research.

[4] L. Lemaire, D. E. Fornwalt, and B. H. Kear, "CoPrecipitation of $\gamma^{\prime}\left(\mathrm{Ni}_{3} \mathrm{Al}\right)$ and $\alpha \mathrm{Cr}$ in a Nickel-Base Alloy", MICROSTRUCTURES, Vol. 2, No. 1, December/January 1971. 